\title{
Patient Exposure Through a Free Community Pre- Exposure Prophylaxis (PrEP) Clinic Improves Medical Student Comfort With Sexual Health and LGBTQIA+ Topics
}

Richard A. Knecht ( $\square$ richard.knecht@hsc.utah.edu )

University of Utah Hospital

Claire M. Lu

University of Utah Hospital

Sierra R. McLean

University of Utah Hospital

\section{J. Skylar Westerdahl}

University of Utah Hospital

Adam M. Spivak

University of Utah Hospital

Susana Keeshin

University of Utah Hospital

\section{Research Article}

Keywords: Sexual health, Pre-exposure prophylaxis, Medical student education, HIV/AIDS, LGBTQIA+

Posted Date: April 26th, 2021

DOI: https://doi.org/10.21203/rs.3.rs-428250/v1

License: (c) (i) This work is licensed under a Creative Commons Attribution 4.0 International License.

Read Full License 


\section{Abstract}

Background: Pre-exposure prophylaxis (PrEP) is an established preventative measure for HIV transmission, however not enough providers are prescribing PrEP for their patients. Reasons for inadequate PrEP coverage include discomfort among providers addressing sexual health and lack of adequate sexual health training among medical trainees.

Objective: Our aim was to determine if volunteer experience in a free PrEP clinic improved medical student knowledge and comfort level addressing sexual health and PrEP with patients.

Methods: An online survey was conducted to determine knowledge and comfort of PrEP, general sexual and LGBTQIA+ health knowledge among medical students who had and had not volunteered at our free PrEP clinic.

Results: 269 students across all four years of medical school were surveyed. Demographics among the two groups were similar. Across the 10 primary survey questions assessing comfort with sexual health and PrEP, those who had volunteered reported significantly more comfort than students who had not. Responses between the two groups differed in the proportion of respondents who reported "extremely" or "very" comfortable with these sexual health topics. There were several affirming narratives provided by students regarding the importance of the PrEP clinic in their medical education. There was no difference between the groups in terms of general sexual health knowledge.

Conclusions: This study demonstrates that volunteering at a PrEP clinic correlated with higher reported comfort with sexual health, including discussions surrounding PrEP. Given the importance of addressing sexual health topic with patients, we conclude that medical students would benefit from more in-person opportunities to learn about sexual health. This study illustrates the importance of exposure in generating comfort for trainees on sensitive topics which could lead to better sexual health care for patients.

\section{Introduction}

First approved in 2012 as an effective and safe method for HIV prevention, Pre-Exposure Prophylaxis (PrEP) reduces HIV sexual transmission by $99 \%$ if taken daily $(1,2)$. While Emtricitabine/Tenofovir is highly efficacious in preventing HIV infection, PrEP prescriptions and discussions about PrEP are not adequately offered to patients(3). Furthermore, providers often cite discomfort with sexual health discussions and discomfort with PrEP specifically ${ }^{3}$. A recent review found that patients were more comfortable than their providers in talking about their sexual health, and providers often reported feeling uncomfortable with both their expertise in discussing sexual health and in addressing sexual health concerns(4). More exposure, training, and education for providers on sexual health topics have been proposed to solve barriers for adequate sexual health services(5). Medical students have reported that educational experiences that included patients were the most effective in their sexual health education. The same survey showed that $21 \%$ had access to sexual health clinics during their education (6). 
Sexual health education in medical school varies widely in quantity and quality. Surveys conducted in 2014 among US medical schools showed that 55\% reported having a dedicated sexual health curriculum. Among schools with a sexual health curriculum, an average of 8 hours was spent teaching sexual health topics. When surveyed, $65 \%$ of first-year medical students felt underprepared when asked to take a sexual health history. This did not improve by the third or fourth year with less than half of students reporting feeling comfortable discussing sexual health with their patients (7). Medical students see sexual health as an important part of their educations' and want more of it (8).

The lack of a defined curriculum for sexual health is especially evident when considering the dearth of training medical students receive concerning lesbian, gay, bisexual, transgendered, queer, intersex, and asexual (LGBTQIA+) health. In a 2011 survey of 176 US medical schools, 33\% reported zero curriculum hours teaching LGBTQIA + specific health topics. Furthermore, among 16 domains of LGBTQIA + specific health issues, only 83 schools reported teaching half (8) of those topics, and only 11 schools reported teaching all 16 topics (9).

Among attending physicians, comprehensive sexual health screenings are rarely performed (10-12). Furthermore, students, trainees and attending physicians alike are influenced by their direct exposure to sexual health training. Students are unlikely to ask about sexual health at the extremes of age, are unlikely to screen men who have oral sex with men for STIs, and only $75 \%$ would screen asymptomatic sexually active females for STIs ${ }^{6}$. Additionally, studies show that providers are more likely to perform sexual health histories, are more comfortable with sexual health topics, more comfortable with special populations and are more likely to prescribe risk modifying therapies such as PrEP when they have prior exposure to training on sexual health or PrEP guidelines(13-15).

While much research describes the lack of a specific sexual health curriculum in graduate medical education and calls for more standardized methods of teaching sexual health (6), (7), (13), there has yet to be a unified strategy for sexual health education in US medical schools. The aim of our study is to demonstrate that medical student exposure to sexual health topics in a free student-run PrEP clinic, which serves a mainly LGBTQIA + patient population, improves attitudes around sexual health screening, increases comfort in medical trainees with sensitive topics such as sexual and LGBTQIA + health and increases awareness for LGBTQIA + health issues.

\section{Methods}

From November 2019 to January 2020 we conducted an anonymous, electronic survey of medical students at the University of Utah School of Medicine. We developed and distributed a survey using a REDCap online survey tool and emailed the survey to students across all 4 years of the medical school student body. REDCap is a Health Information Privacy and Accountability Act compliant, online survey tool used in clinical research (https://www.project-redcap.org/). The survey had ten questions representing self-reported comfort with various sexual health topics and six questions covering basic sexual health knowledge. The survey asked students for demographics including age, ethnic/racial and 
gender identity, number of children, as well as current medical school year, whether they had volunteered in the free PrEP clinic, whether they had prior sexual health education.

The ten-question survey concerning sexual-health topic comfort asked students to self-report their comfort level obtaining a sexual health history from a patient, discussing safe sexual practices, evaluating patients for STI transmission risk factors, using sexual slang, and counseling patients on safe sex. Two of these ten questions referred to the students' self-reported comfort regarding the LGBTQIA + community. Two questions assessed students' self-reported comfort with CDC HIV testing and PrEP guidelines. Self-reported questions were graded using a 5-point Likert scale using terms of "not at all, slightly, moderately, very or extremely" with regard to comfort level. Topics that assessed sexual health knowledge on HIV transmission, HIV symptoms, pregnancy transmission, HIV testing and access to PrEP asked for a simple yes or no response.

Results were tabulated across the four years and evaluated in two cohorts: one with volunteer experience at the free PrEP clinic and the other without. Using a Likert scale, responses for comfort questions were assigned 1 for "not at all", 2 for "slightly", 3 for "moderately", 4 for "very" and 5 for "extremely". The mean response of each group, for each question, was calculated and compared with the average response of the other group. A simple T-Test was calculated to assess statistical significance in the average response for each group. Chi squared analysis was used for hypothesis testing of any categorical data.

\section{Results}

Across the four medical school classes there were 269 respondents. By year in medical school, 89 (33.1\%) were first-years, 72 (26.8\%) second years, 44 (16.3\%) third years, and 64 (23.8\%) fourth year students. Of the total students; $17 \%$ (44) had volunteered at least once in PrEP clinic; $52 \%$ (123) identified as female, $80 \%$ (216) were white and the mean age was 26.5 years. Females $(73 \%)$ volunteered more in the PrEP clinic. Respondents who did not volunteer were evenly distributed by gender. There was no statistical difference in age between the two groups. With regards to religion, 103 (38.3\%) identified as Christian. Of those who identified as Christian, 82 (81\%) identified with The Church of Jesus Christ of Latter-day Saints, $11(11 \%)$ as protestant, and 7 (6\%) as Catholic. We found a difference in the religious identity between groups. Those who identified as members of The Church of Jesus Christ of Latter-day Saints were less likely to have volunteered. There was no statistical difference between those who volunteered and those who did not on the basis of race, marital status, or parental status. There was also no difference in those who had volunteered and those who had/not participated in supplementary sexual health education. Demographics data are listed in Table 1. 
Table 1

Student Demographics

\begin{tabular}{|c|c|c|c|c|}
\hline Variable & $\begin{array}{l}\text { Volunteered } \\
(\mathrm{N}=44)\end{array}$ & $\begin{array}{l}\text { Never } \\
\text { Volunteered } \\
(\mathrm{N}=225)\end{array}$ & $\begin{array}{l}\text { Chi square statistic or } \\
\text { *TTEST }\end{array}$ & $\begin{array}{l}P \\
\text { value }\end{array}$ \\
\hline \multicolumn{5}{|l|}{ Age } \\
\hline $\begin{array}{l}\text { Age, mean (IQR) } \\
\text { Gender identity } \mathbf{n}(\%)\end{array}$ & $\begin{array}{l}26.61(25- \\
28)\end{array}$ & $26.5(24-28)$ & * & 0.98 \\
\hline Female, n (\%) & $32(73 \%)$ & $107(48 \%)$ & 8.19 & 0.01 \\
\hline Male, n (\%) & $12(27 \%)$ & $110(49 \%)$ & & \\
\hline $0(0 \%)$ & $8(3 \%)$ & & & \\
\hline Religion n (\%) & & & 20.069 & 0.017 \\
\hline Atheist & $4(9 \%)$ & $23(10 \%)$ & & \\
\hline Later Day Saint (LDS) & $6(13 \%)$ & $78(34 \%)$ & & \\
\hline Nothing in particular & $16(37 \%)$ & $51(23 \%)$ & & \\
\hline Do not wish to respond & $3(7 \%)$ & $25(11 \%)$ & & \\
\hline Agnostic & $4(9 \%)$ & $26(12 \%)$ & & \\
\hline Roman Catholic & $2(4 \%)$ & $6(3 \%)$ & & \\
\hline Buddhist & $0(0)$ & $1(0.4 \%)$ & & \\
\hline Protestant & $5(11 \%)$ & $6(3 \%)$ & & \\
\hline Muslim & $0(0)$ & $2(0.8 \%)$ & & \\
\hline Hindu & $1(2 \%)$ & $3(1 \%)$ & & \\
\hline Jewish & $2(4 \%)$ & $2(0.8 \%)$ & & \\
\hline Other & $1(2 \%)$ & $2(0.08 \%)$ & & \\
\hline Racial identity n (\%) & & & 9.496 & 0.147 \\
\hline Hispanic or Latinx & $1(2 \%)$ & $7(15 \%)$ & & \\
\hline American Indian & 0 & 0 & & \\
\hline Asian & $3(7 \%)$ & $17(7 \%)$ & & \\
\hline $\begin{array}{l}\text { Native Hawaiian or Pacific } \\
\text { Islander }\end{array}$ & 0 & $1(0.4 \%)$ & & \\
\hline Black or African American & 0 & $3(1 \%)$ & & \\
\hline
\end{tabular}




\begin{tabular}{|c|c|c|c|c|}
\hline Variable & $\begin{array}{l}\text { Volunteered } \\
(\mathrm{N}=44)\end{array}$ & $\begin{array}{l}\text { Never } \\
\text { Volunteered } \\
(\mathrm{N}=225)\end{array}$ & $\begin{array}{l}\text { Chi square statistic or } \\
\text { *TTEST }\end{array}$ & $\begin{array}{l}P \\
\text { value }\end{array}$ \\
\hline White & $39(88 \%)$ & 177 (78\%) & & \\
\hline Other & $1(2 \%)$ & $7(3)$ & & \\
\hline \multicolumn{5}{|l|}{ Marital status n (\%) } \\
\hline Single & $24(55 \%)$ & $94(43 \%)$ & 6.618 & 0.08 \\
\hline Married & $11(25 \%)$ & 87 (39\%) & & \\
\hline Partnered & $8(18 \%)$ & $44(20 \%)$ & & \\
\hline Divorced & $1(2 \%)$ & 0 & & \\
\hline Have children n (\%) & & & 1.038 & 0.30 \\
\hline Yes & $5(11 \%)$ & $39(17 \%)$ & & \\
\hline No & 39 (89\%) & $186(83 \%)$ & & \\
\hline \multicolumn{5}{|l|}{ Any prior training in: $\mathbf{n}(\%)$} \\
\hline Taking a sexual history & $18(41 \%)$ & $98(43 \%)$ & 1.732 & 0.63 \\
\hline Sexual health/education & $12(27 \%)$ & $56(25 \%)$ & & \\
\hline $\begin{array}{l}\text { Pre-Exposure Prophylaxis } \\
\text { (PrEP) }\end{array}$ & $12(27 \%)$ & $37(16 \%)$ & & \\
\hline LGBTQIA + health & $6(14 \%)$ & $28(12 \%)$ & & \\
\hline
\end{tabular}

Students were asked to report their comfort with 10 sexual health topics. Those students who had volunteered at the PrEP clinic differed significantly in comfort than those who had not volunteered. Students that volunteered had a much higher comfort score on all 10 topics (Table 2.). Those topics were: taking a sexual health history from patients, discussing safe sexual practices with patients, evaluating patients for HIV risk factors, providing counseling to patients on methods to reduce transmission of STIs or HIV, discussing PrEP with patients, using sexual slang when taking a sexual history (i.e. bottom, top, vers, etc. ), taking a sexual history from LGBTQIA + patients, discussing safe sexual practices with LGBTQIA + patients, familiarity with the 2014 CDC recommendations for HIV testing, and familiarity with the most recent CDC guidelines for pre-exposure prophylaxis (PrEP) for HIV. Results are given in greater detail in Table 2. 
Table 2

Average responses for each group on the 10 comfort questions

\begin{tabular}{|c|c|c|c|}
\hline Variable & $\begin{array}{l}\text { Volunteered } \\
(\mathrm{N}=44)\end{array}$ & $\begin{array}{l}\text { Never Volunteered } \\
(\mathrm{N}=225)\end{array}$ & $p$ value \\
\hline \multicolumn{4}{|c|}{ Topic (mean response out of 5) $(95 \% \mathrm{Cl})$} \\
\hline 1 & $3.79(3.53-4.04)$ & $3.39(3.26-3.51)$ & 0.05 \\
\hline 2 & $3.63(3.30-3.96)$ & $3.14(3.01-3.29)$ & 0.002 \\
\hline 3 & $3.79(3.46-4.11)$ & $2.91(2.75-3.07)$ & $<0.001$ \\
\hline 4 & $3.81(3.45-4.16)$ & $3.05(2.9-3.20)$ & $<0.001$ \\
\hline 5 & $3.93(3.6-4.26)$ & $2.51(2.34-2.67)$ & $<0.001$ \\
\hline 6 & $3.57(3.22-3.92)$ & $2.35(2.19-2.5)$ & $<0.001$ \\
\hline 7 & $3.72(3.41-4.04)$ & $2.81(2.67-2.96)$ & $<0.001$ \\
\hline 8 & $3.61(3.27-3.95)$ & $2.67(2.52-2.81)$ & $<0.001$ \\
\hline 9 & $2.59(2.23-2.95)$ & $1.96(1.82-2.1)$ & 0.002 \\
\hline 10 & $2.82(2.47-3.17)$ & $1.87(1.73-2.0)$ & $<0.001$ \\
\hline \multicolumn{4}{|c|}{ Abbreviations: $\mathrm{SD}=$ standard deviation, $95 \% \mathrm{Cl}=95 \%$ confidence interval. } \\
\hline \multicolumn{4}{|c|}{$\begin{array}{l}\text { Topic 1: taking a sexual health history from patients. Topic 2: discussing safe sexual practices with } \\
\text { patients. Topic } 3 \text { : evaluating patients for HIV risk factors. Topic } 4 \text { : providing counseling to patients on } \\
\text { methods to reduce transmission of STIs or HIV. Topic 5: discussing pre-exposure prophylaxis (PrEP) } \\
\text { with patients. Topic } 6 \text { : using sexual slang when taking a sexual history (i.e. bottom, top, vers, etc.). } \\
\text { Topic 7: taking a sexual history from LGBTQIA + patients. Topic 8: discussing safe sexual practices } \\
\text { with LGBTQIA + patients. Topic: How familiar, if at all, are you with the } 2014 \text { CDC recommendations } \\
\text { for HIV testing? Topic 10: How familiar, if at all, are you with the } 2017 \text { CDC recommendations for pre- } \\
\text { exposure prophylaxis (PrEP) for HIV? }\end{array}$} \\
\hline
\end{tabular}

Additionally, the relative proportion of students reporting comfort levels of "extremely" or "very" comfortable with various sexual health topics when delivering patient care was higher in the group of students that volunteered. For example, $25 \%$ or greater of students who had volunteered reported being "extremely comfortable" on 8 of the 10 self-reported comfort topics. Furthermore, only $10 \%$ or more of the students who had volunteered reported feeling "not at all" comfortable on only 2 of the 10 topics. In contrast, only $12 \%$ or greater of students who had not volunteered reported feeling "extremely" comfortable on only 2 of the 10 self-reported comfort topics. Those that had not volunteered reported feeling "not at all" comfortable greater than $15 \%$ of the time in 5 of the 10 topics (Table 3). Even when adjusting for gender, age, racial/ethnic identity, marital status and year in medical school by logistic regression analysis, those who volunteered in PrEP clinic had an increased comfort level on all sexual health topics. This distribution is represented in Table 3. 
Table 3

Comfort level by group broken down by individual self-report

\begin{tabular}{|c|c|c|c|c|}
\hline Variable & $\begin{array}{l}\text { Volunteered } \\
(\mathrm{N}=44)\end{array}$ & $\begin{array}{l}\text { Never } \\
\text { Volunteered } \\
(\mathrm{N}=225)\end{array}$ & $\begin{array}{l}\text { Chi } \\
\text { square } \\
\text { statistic } \\
\text { or } \\
\text { *TTEST }\end{array}$ & $\begin{array}{l}P \\
\text { value }\end{array}$ \\
\hline \multicolumn{5}{|l|}{ Topic n (\%) } \\
\hline taking a sexual health history from patients & & & 13.567 & 0.0088 \\
\hline 0 & $7(3 \%)$ & & & \\
\hline $1(2 \%)$ & $25(11 \%)$ & & & \\
\hline $17(39 \%)$ & $98(44 \%)$ & & & \\
\hline $15(34 \%)$ & $66.8(30 \%)$ & & & \\
\hline $11(25 \%)$ & $28(13 \%)$ & & & \\
\hline discussing safe sexual practices with patients. & & & 20.069 & 0.022 \\
\hline $1(2 \%)$ & $12(5 \%)$ & & & \\
\hline $6(14 \%)$ & $46(20 \%)$ & & & \\
\hline $12(27 \%)$ & $88(40 \%$ & & & \\
\hline $14(32 \%)$ & $53(24 \%)$ & & & \\
\hline $11(25 \%)$ & $24(11 \%)$ & & & \\
\hline \multicolumn{5}{|l|}{ evaluating patients for HIV risk factors } \\
\hline 0 & $24(11 \%)$ & 24.727 & $<0.001$ & \\
\hline $6(14 \%)$ & $67(30 \%)$ & & & \\
\hline $11(26 \%)$ & $59(27 \%)$ & & & \\
\hline $12(28 \%)$ & $49(22 \%)$ & & & \\
\hline $14(33 \%)$ & $24(11 \%)$ & & & \\
\hline \multicolumn{5}{|l|}{$\begin{array}{l}\text { providing counseling to patients on methods to } \\
\text { reduce transmission of STIs or HIV }\end{array}$} \\
\hline $1(2 \%)$ & $22(10 \%)$ & 15.798 & 0.003 & \\
\hline $5(11 \%)$ & $50(23 \%)$ & & & \\
\hline $11(25 \%)$ & $71(32 \%)$ & & & \\
\hline $11(25 \%)$ & $52(23 \%)$ & & & \\
\hline
\end{tabular}




\begin{tabular}{|c|c|c|c|c|}
\hline Variable & $\begin{array}{l}\text { Volunteered } \\
(\mathrm{N}=44)\end{array}$ & $\begin{array}{l}\text { Never } \\
\text { Volunteered } \\
(\mathrm{N}=225)\end{array}$ & $\begin{array}{l}\text { Chi } \\
\text { square } \\
\text { statistic } \\
\text { or } \\
\text { *TTEST }\end{array}$ & $\begin{array}{l}P \\
\text { value }\end{array}$ \\
\hline $16(37 \%)$ & $27(12 \%)$ & & & \\
\hline \multicolumn{5}{|l|}{$\begin{array}{l}\text { discussing pre-exposure prophylaxis (PrEP) with } \\
\text { patients. }\end{array}$} \\
\hline 0 & $59(26 \%)$ & 54.483 & $<0.001$ & \\
\hline $6(14 \%)$ & $63(28 \%)$ & & & \\
\hline $8(19 \%)$ & $48(21 \%)$ & & & \\
\hline $12(28 \%)$ & $37(16 \%)$ & & & \\
\hline $17(39 \%)$ & $17(8 \%)$ & & & \\
\hline \multicolumn{5}{|l|}{$\begin{array}{l}\text { using sexual slang when taking a sexual history } \\
\text { (i.e. bottom, top, vers, etc.). }\end{array}$} \\
\hline $3(7 \%)$ & $61(27 \%)$ & 48.46 & $<0.001$ & \\
\hline $4(9 \%)$ & $78(35 \%)$ & & & \\
\hline $12(27 \%)$ & $45(20 \%)$ & & & \\
\hline $15(34 \%)$ & $24(11 \%)$ & & & \\
\hline $10(23 \%)$ & $16(7 \%)$ & & & \\
\hline \multicolumn{5}{|l|}{ taking a sexual history from LGBTQIA + patients } \\
\hline $1(2 \%)$ & $23(10 \%)$ & 27.979 & $<0.001$ & \\
\hline $4(9 \%)$ & $62(28 \%)$ & & & \\
\hline $15(34 \%)$ & $81(36 \%)$ & & & \\
\hline $11(25 \%)$ & $38(17 \%)$ & & & \\
\hline $13(30 \%)$ & $19(9 \%)$ & & & \\
\hline $\begin{array}{l}\text { discussing safe sexual practices with LGBTQIA + } \\
\text { patients. }\end{array}$ & & & 41.662 & $<.001$ \\
\hline $1(2 \%)$ & $35(16 \%)$ & & & \\
\hline $7(7 \%)$ & 63 (29\%) & & & \\
\hline $12(27 \%)$ & 76 (35\%) & & & \\
\hline $12(27 \%)$ & 32 (15\%) & & & \\
\hline
\end{tabular}




\begin{tabular}{|c|c|c|c|c|}
\hline Variable & $\begin{array}{l}\text { Volunteered } \\
(\mathrm{N}=44)\end{array}$ & $\begin{array}{l}\text { Never } \\
\text { Volunteered } \\
(\mathrm{N}=225)\end{array}$ & $\begin{array}{l}\text { Chi } \\
\text { square } \\
\text { statistic } \\
\text { or } \\
\text { *TTEST }\end{array}$ & $\begin{array}{l}P \\
\text { value }\end{array}$ \\
\hline
\end{tabular}

12 (27\%)

$13(6 \%)$

How familiar, if at all, are you with the 2014 CDC recommendations for HIV testing?

$\begin{array}{llll}10(23 \%) & 101(45 \%) & 15.659 & 0.004 \\ 11(25 \%) & 53(24 \%) & & \\ 12(27 \%) & 51(23 \%) & \\ 9(20 \%) & 14(6 \%) & \\ 2(4 \%) & 4(2 \%) & \\ \begin{array}{l}\text { How familiar, if at all, are you with the 2017 CDC } \\ \text { recommendations for pre-exposure prophylaxis } \\ \text { (PrEP) for HIV? }\end{array} & \\ 7(16 \%) & 108(48 \%) & 33.849 \\ 9(20 \%) & 57(25 \%) & \\ 16(36 \%) & 43(19 \%) & \\ 9(20 \%) & 13(6 \%) & \\ 3(7 \%) & 23(1 \%) & \\ & & \end{array}$

For the six knowledge-based questions, there was no statistically significant difference in correct responses between students who had volunteered at the PrEP clinic and those who had not. The average correct responses for each of the knowledge questions are represented in Table 4. 
Table 4

Mean correct responses to general sexual knowledge questions

\begin{tabular}{|c|c|c|c|}
\hline Question n (\%) & $\begin{array}{l}\text { Volunteered } \\
(\mathrm{N}=44)\end{array}$ & $\begin{array}{l}\text { Never } \\
\text { Volunteered } \\
(\mathrm{N}=225)\end{array}$ & $\begin{array}{l}P \\
\text { value }\end{array}$ \\
\hline $\begin{array}{l}\text { Can a person with an STI pass it on if they do not have } \\
\text { symptoms? }\end{array}$ & $44(100 \%)$ & $\begin{array}{l}217 \\
(99.6 \%)\end{array}$ & 0.329 \\
\hline Are HIV and AIDS the same thing? & $43(97.7 \%)$ & $\begin{array}{l}221 \\
(98.2 \%)\end{array}$ & 0.414 \\
\hline Will a person infected with HIV always show symptoms? & $42(95.5 \%)$ & $\begin{array}{l}204 \\
(90.6 \%)\end{array}$ & 0.148 \\
\hline $\begin{array}{l}\text { Will a pregnant woman with HIV/AIDS always pass it on } \\
\text { to their unborn child? }\end{array}$ & $42(95.5 \%)$ & $\begin{array}{l}203 \\
(90.5 \%)\end{array}$ & 0.167 \\
\hline $\begin{array}{l}\text { Can a swab of the inside of the cheek be used to test for } \\
\text { HIV? }\end{array}$ & $21(47.7 \%)$ & $97(42.9 \%)$ & 0.277 \\
\hline Is pre-exposure prophylaxis (PrEP) covered by insurance? & $35(79.5 \%)$ & $\begin{array}{l}152 \\
(67.4 \%)\end{array}$ & 0.07 \\
\hline
\end{tabular}

Students were asked to provide narrative comments on their experiences regarding sexual health education during medical school. Of the students who volunteered, there were several affirming comments that volunteering advanced their sexual health knowledge.

-"I feel like almost everything functional that I learned about taking a sexual history came from 1. Being queer and 2. Going to PrEP clinic. I do not think the [University of Utah School of Medicine] curriculum has taught me much about this at all, and sexual history taking is not at all discussed at the other student-run clinics."

-"All of my knowledge on these topics came from sessions I attended through the PrEP clinic, EPAC [Education in Pediatric Across the Continuum], or Layers of Medicine [course taught as part of the preclinical core curriculum]. I would not say that these topics get well covered in general core curriculum or in [clinical methods course]. I loved the orientation session done by the PrEP clinic and think that should be mandatory for all med students".

-"The majority of what l've learned about taking a good sexual history and educating patients on risk reduction, etc. has been directly as a result of working at the PrEP clinic."

Among the students that had not volunteered with the PrEP clinic, there were 13 comments noting a lack of sexual health curriculum, desire to know more or be better trained in sexual health topics and PrEP. Sample narratives: 


\section{-"Would love to see some time dedicated to LGBTQIA + Health, in addition to PrEP."}

-"My knowledge and comfort with discussing and understanding sexual health stem from my own personal experiences and learning I have done on my own. I did not learn these skills from the curriculum at the [University of Utah School of Medicine]. I feel the [University of Utah School of Medicine] has a huge deficit in teaching sexual health."

-"I'm much more comfortable taking sexual histories since I'm gay. Many of my classmates do not know what top/bottom/vers is - these important details are never addressed in the classroom although they should be!"

-"My comfort with taking sexual histories has nothing to do with what I was taught at school. Our training is inadequate and does not teach us anything about LGBTQIA + health."

-"During medical school, I attended one PrEP clinic lecture on taking a sexual history first year and it was my only exposure to the topic until my OB/gyn rotation. On OB/gyn, we were given a brief lecture and able to practice. I now feel capable of taking a sexual history but I would have LOVED more practice with this over the first 2 years and into clerkships as it is such an important skill to talk about sex with patients with a respectful and patient-oriented attitude."

\section{-"Need to brush up on STI treatment and prophylaxis for LGBTQIA + patients."}

\section{-"Very important work, I realize I feel very ignorant in these things."}

\section{-"This made me realize how little I know."}

\section{Discussion}

This survey indicates that students who have experiential learning with real patients, by volunteering in a free PrEP clinic, augment their comfort level around sexual health topics and their interactions with LGBTQIA+ patients. Students that volunteered in the PrEP clinic one or more times had significantly increased comfort in discussing sexual histories and safe sexual practices, evaluating HIV transmission risk factors, counseling on risk reductions of STIs or HIV, and discussing PrEP with patients. Additionally, they have significantly increased comfort discussing sexual health topics with LGBTQIA+ patients. Students who had volunteered in the clinic had significantly increased familiarity with the 2014 and 2017 CDC PrEP guidelines. Answers to six specific knowledge-based questions show a larger percentage of previously volunteered students answering five out of six questions correctly. However, these results were not significantly different between volunteers and non-volunteers. 
This is comparable to previous research that shows early clinical exposure with patients increases students' confidence(16). It also indicates that clinical skills related to comprehensive sexual health and experiences with specific underserved medical populations, like LGBTQIA+ patients, in medical school curriculum are lacking. Although students indicated greater comfort in clinical skills, we did not find a significant difference in knowledge between the two groups indicating some knowledge gaps exist in both volunteers and non-volunteers, particularly related to diagnosing HIV. Our results indicate medical students need additional educational and clinical experiences in other areas of sexual health and wellness.

In a systematic review of how clinical experiences contribute to early medical education, researchers found early clinical exposure positively impacted medical students' confidence in interviewing patients, communication and clinical skills, and individual patient satisfaction ${ }^{16}$. Our survey results further contribute to the growing body of research demonstrating that medical students and patients benefit from early clinical exposure to LGBTQIA+ patient interactions ${ }^{13-15}$. Additionally, LGBTQIA+ patients have indicated in prior research that they value competent respectful providers, who listen to patients, and are educated about HIV transmission and prevention ${ }^{11}$. LGBTQIA+ patients have also indicated that some of their most important health concerns are STDs, HIV/AIDs, and safe sex(17).

Medical school curriculums are historically lacking in comprehensive sexual education, putting students at a disadvantage when treating future LGBTQIA+ patients ${ }^{3}$. Providers in the US already lack the training to provide comprehensive sexual health care, especially for LGBTQIA+ patients(18). Our research indicates clinical experiences with sexual health care enables students to become competent sexual health care providers. Ideally, medical school curriculums should incorporate more exposure to clinical experiences for students to assess and provide comprehensive sexual health care.

A published study in 2011 reports the doubling time for medical knowledge in 2020 is 73 days ${ }^{7}$. HIV prevention, diagnosis, and treatment is an especially rapidly growing medical field, and current medical school curriculums and the PrEP clinic are not enough to bridge the gaps in knowledge about the diagnostics of HIV. Based on student comments, there is a need for assessment and improved delivery of current knowledge in rapidly changing clinical knowledge areas, like HIV, for students.

Limitations of our research include the number of volunteers at the clinic is much smaller than the group that had not volunteered. Additionally, our survey only assesses students at one point in time, and there may be selection bias in students who self-select to volunteer at the clinic. Future research should follow up with students to determine overall comfort levels as they continue volunteering in the free community PrEP clinic and progressing through medical school.

Overall, our results add to the body of research that a non-standardized medical school curriculum lacks in knowledge and experiences related to treating LGBTQIA+ patients, and comprehensive sexual health ${ }^{9,18}$. Prior research also indicates that residents perceive a lack of provider training and education regarding PrEP, which is a perceived barrier to prescribing PrEP, thereby reducing patient access to PrEP

Page $13 / 16$ 
10. Although a free clinic may not be a feasible learning opportunity for students, experience with PrEP in clinical settings with real patients should be integrated into medical school curriculum. This would help students become providers who are familiar and comfortable prescribing PrEP and addressing sexual health topics. The gaps in up to date knowledge surrounding the treatment and diagnosis of HIV are present in students, and medical school education needs to reform their sexual health curriculum's importance and content.

\section{Declarations}

\section{Funding:}

None

\section{Ethics approval and consent to participate:}

Ethical approval was obtained by the University of Utah Institutional Review Board for use of data involving human subjects. Approval date: 10/8/2019. Reference number: IRB_00125676

All methods were carried out in accordance with relevant guidelines and regulations.

\section{Consent for publication:}

All subjects gave informed consent detailing their participation in this research study

\section{Availability of data and materials:}

The datasets used and/or analyzed during the current study are available from the corresponding author on reasonable request.

\section{Competing interests:}

None

\section{Authors' contributions:}

RAK aided in creating the survey, collected data, analyzed data, wrote portions of the manuscript, edited the manuscript, created tables/figures.

CML aided in creating the survey, collected data, analyzed data, wrote portions of the manuscript, edited the manuscript, created tables/figures.

SRM aided in creating the survey, collected data, analyzed data, wrote portions of the abstract and reviewed the manuscript.

SJW aided in creating the survey, distributed the survey and collected data. 
AMS advised how research was conducted, reviewed and edited the manuscript.

SK acted as principal investigator, advised how research was conducted, aided in data analysis and edited the manuscript.

\section{Acknowledgements:}

None

\section{References}

1. Riddell Jt, Amico KR, Mayer KH. HIV Preexposure Prophylaxis: A Review. JAMA. 2018;319(12):12618.

2. McCormack S, Dunn DT, Desai M, Dolling DI, Gafos M, Gilson R, et al. Pre-exposure prophylaxis to prevent the acquisition of HIV-1 infection (PROUD): effectiveness results from the pilot phase of a pragmatic open-label randomised trial. Lancet. 2016;387(10013):53-60.

3. Pleuhs B, Quinn KG, Walsh JL, Petroll AE, John SA. Health Care Provider Barriers to HIV Pre-Exposure Prophylaxis in the United States: A Systematic Review. AIDS Patient Care STDS. 2020;34(3):111-23.

4. Zhang X, Sherman L, Foster M. Patients' and providers' perspectives on sexual health discussion in the United States: A scoping review. Patient Educ Couns. 2020;103(11):2205-13.

5. Parish SJ, Clayton AH. Sexual medicine education: review and commentary. J Sex Med. 2007;4(2):259-67; quiz 68.

6. Malhotra S, Khurshid A, Hendricks KA, Mann JR. Medical school sexual health curriculum and training in the United States. J Natl Med Assoc. 2008;100(9):1097-106.

7. Criniti S, Andelloux M, Woodland MB, Montgomery OC, Hartmann SU. The State of Sexual Health Education in U.S. Medicine. American Journal of Sexuality Education. 2014;9(1):65-80.

8. Turner D, Nieder TO, Dekker A, Martyniuk U, Herrmann L, Briken P. Are medical students interested in sexual health education? A nationwide survey. Int J Impot Res. 2016;28(5):172-5.

9. Obedin-Maliver J, Goldsmith ES, Stewart L, White W, Tran E, Brenman S, et al. Lesbian, gay, bisexual, and transgender-related content in undergraduate medical education. JAMA. 2011;306(9):971-7.

10. Sargant NN, Smallwood N, Finlay F. Sexual history taking: a dying skill? J Palliat Med. 2014;17(7):829-31.

11. Balami J, Gosney MA, Van Wyk A. Are geriatricians guilty of omitting to take a sexual history?...British Geriatrics Society: Abstracts of papers presented at the Spring Scientific Meeting, 67 April 2006. Age \& Ageing. 2006;35:i62-i.

12. McCool ME, Apfelbacher C, Brandstetter S, Mottl M, Loss J. Diagnosing and treating female sexual dysfunction: a survey of the perspectives of obstetricians and gynaecologists. Sex Health. 2016;13(3):234-40. 
13. Rubin ES, Rullo J, Tsai P, Criniti S, Elders J, Thielen JM, et al. Best Practices in North American PreClinical Medical Education in Sexual History Taking: Consensus From the Summits in Medical Education in Sexual Health. J Sex Med. 2018;15(10):1414-25.

14. Terndrup C, Streed CG, Jr., Tiberio P, Black M, Davis J, Apfel A, et al. A Cross-sectional Survey of Internal Medicine Resident Knowledge, Attitudes, Behaviors, and Experiences Regarding Pre-Exposure Prophylaxis for HIV Infection. J Gen Intern Med. 2019;34(7):1258-78.

15. Frasca K, Castillo-Mancilla J, McNulty MC, Connors S, Sweitzer E, Zimmer S, et al. A Mixed Methods Evaluation of an Inclusive Sexual History Taking and HIV Prevention Curriculum for Trainees. J Gen Intern Med. 2019;34(7):1279-88.

16. Dornan T, Littlewood S, Margolis SA, Scherpbier A, Spencer J, Ypinazar V. How can experience in clinical and community settings contribute to early medical education? A BEME systematic review. Med Teach. 2006;28(1):3-18.

17. Hoffman ND, Freeman K, Swann S. Healthcare preferences of lesbian, gay, bisexual, transgender and questioning youth. J Adolesc Health. 2009;45(3):222-9.

18. Warner C, Carlson S, Crichlow R, Ross MW. Sexual Health Knowledge of U.S. Medical Students: A National Survey. J Sex Med. 2018;15(8):1093-102. 